\title{
A Psychiatric Perspective on Erectile Dysfunction
}

Syed Ahmed, MD

UTMB, Galveston Texas

Follow this and additional works at: https://jdc.jefferson.edu/jeffjpsychiatry

Part of the Psychiatry Commons

Let us know how access to this document benefits you

\section{Recommended Citation}

Ahmed, MD, Syed (1988) "A Psychiatric Perspective on Erectile Dysfunction," Jefferson Journal of Psychiatry. Vol. 6 : Iss. 1 , Article 9.

DOI: https://doi.org/10.29046/JJP.006.1.007

Available at: https://jdc.jefferson.edu/jeffjpsychiatry/vol6/iss1/9

This Article is brought to you for free and open access by the Jefferson Digital Commons. The Jefferson Digital Commons is a service of Thomas Jefferson University's Center for Teaching and Learning (CTL). The Commons is a showcase for Jefferson books and journals, peer-reviewed scholarly publications, unique historical collections from the University archives, and teaching tools. The Jefferson Digital Commons allows researchers and interested readers anywhere in the world to learn about and keep up to date with Jefferson scholarship. This article has been accepted for inclusion in Jefferson Journal of Psychiatry by an authorized administrator of the Jefferson Digital Commons. For more information, please contact: JeffersonDigitalCommons@jefferson.edu. 


\title{
A Psychiatric Perspective on Erectile Dysfunction
}

\author{
Syed Ahmed, M.D.
}

Erectile impotence is a common family health problem, with exact incidence unknown, that adversely affects both men and their female partners. It is classified as "inhibited sexual excitement" in DSM-III and is defined as the inability to attain or maintain a penile erection until completion of the sexual act. It had been stated formerly, without supporting evidence, that $90 \%$ of erectile disorders were "psychogenic." Today, however, only about one-third are so classified (1). In Kinsey's (2) series, the prevalence of impotence was less than $2 \%$ until the age of 40 years; it increased to $6-7 \%$ at age 55 and by age 70 years more than one-fourth of males reported long-term erectile incompetency. It is not certain to what extent this increased prevalence of erectile disorder concurrent with aging is indicative of mental conditions, or covert medical conditions or the natural biological changes induced by aging. Impotence ordinarily is classified as: 1) primary (life long), or secondary (acquired after satisfactory potency); 2) partial or total; 3) generalized or situational.

\section{PSYCHIATRIC MEANING OF ERECTILE DISORDER}

Men have varying degrees of a "he-man" image that is maintained by the ability to have erections adequate for sexual intercourse. The onset of erectile disorder, therefore, produces narcissistic injury and depression. Regardless of the cause of erectile disorder, there is often a psychical overlay, substrate, correlate, or sequel.

Psychoanalytic formulations (3) indicate unconscious intrapsychic conflicts rooted in unresolved Oedipal problems, with a defense against incest-guilt and consequent castration anxiety or a defense against unconscious hostility and sadistic impulses toward women. Feelings of masculine inadequacy and unconscious homosexual fixation are also implicated as causative factors in erectile disorder. Masters and Johnson (4) reported three cases of primary impotence with a history of specific sexual overtures by their mothers.

Systems Theory formulations (5) stress the role of dyadic factors as crucial in the genesis of erectile disorders, or in their resolution. In a destructive relationship, a woman can indeed enact the classic picture of "the castrating female," but most "castrating females" exist only in the eye of the beholder.

Dr. Ahmed is a fourth year resident at UTMB, Galveston, Texas. 
Loss of physical attraction of patients' sexual partners is also an important contributory factor in causing this disorder. A man in his fifties with erectile dysfunction reported benefit from sex therapy, but the resolution of his problem did not last, since he labeled his wife "ugly." Another man reported having adequate erections while masturbating but not at the time of intercourse with his girlfriend, for she was demanding, degrading and humiliating towards him.

Learning Theory formulations (5) focus on the special social phobia that may play a role in some cases of erectile disorder. For example, some men are phobic toward the woman's genitals ("vagina dentata" fears) or a specific aspect of these such as fear of vaginal secretions or the genital aroma. A 19 year old man who presented a history of erectile disorder reported that he had a constant fear of impregnating his girlfriend whom he suspected of having mixed something in his drink to make him impotent.

\section{CONCEPT OF PERFORMANCE ANXIETY}

The fear of failure, as well as fear of abandonment by the partner, is regarded as a powerful "castrator" $(4,5)$. Male sexual response may be considered a cyclic phenomenon, starting with fantasy (appetitive phase) and terminating in the resolution phase. Resolution through orgasm is characterized by a subjective sense of well-being. This sense of euphoria and pleasure in the entire successful sexual experience serves to enhance the fantasy during the next sexual response. The onset of erectile failure impairs the normal sexual response and in fact leads to performance anxiety. Circumstances such as depression, true organic onset, marital discord, economic setback, and alcoholism-called "Situational Factors" in Figure 1-may trigger an erectile failure which then becomes the nidus for the development of severe performance anxiety and a vicious cycle of successive failures.

\section{ASSESSMENT}

Men with this disorder have a variety of different feelings when referred for psychiatric evaluation. Some have a positive attitude, others are quite indifferent and some apprehensive, especially those who are not prepared to accept an emotional or mental cause for their problems. With the onset of men's erectile disorder, women start feeling that their partners have lost interest in them and have started seeing someone else. It is common for pathological jealousy to occur which simply compounds the problem.

A thorough assessment of erectile dysfunction requires a full exploration and understanding of both inner and outer dynamic forces which have contributed to the development of the patient's symptoms. It is particularly important to trace carefully the circumstances under which the symptom first made its appearance. This often provides major clues to the understanding of the psychodynamic significance of the symptom and the reasons for its existence. A 


\section{DYNAMICS OF PERFORMANCE ANXIETY}
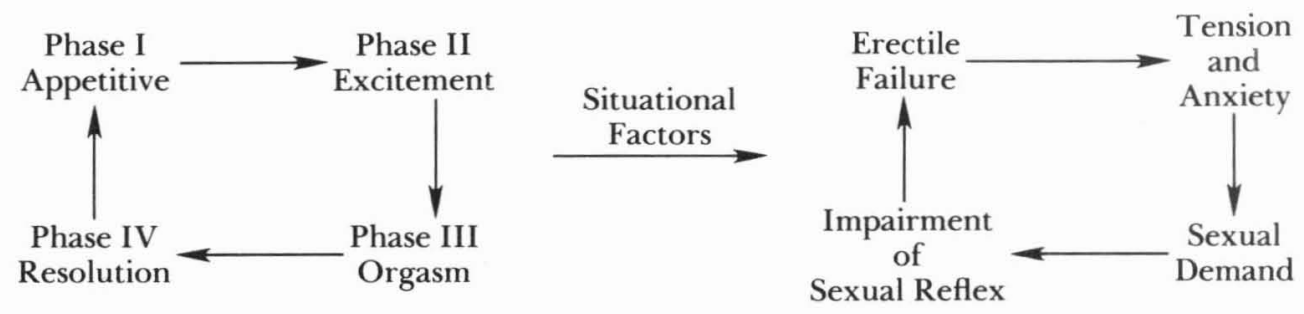

direct relationship between "psychological" or symbolic factors, and erectile dysfunction is not very well understood. To identify positive evidence of symbolic involvement, not only are psychiatric interviews necessary, but also such measures as nocturnal penile tumescence (NPT) monitoring and MMPI profile are called for. Cavernosal alpha-blockade has recently been indicated for the same purpose (6).

Fisher (7) and Karacan (8) made the first serious attempt to measure nocturnal penile tumescence (NPT) to distinguish between the two groups, a study that was criticized for using NPT data to assign patients to diagnostic categories. Peter Marshall (9) studied maximum erectile response and maximum frequency of nocturnal erections as two criteria in providing first-stage validation of NPT as a diagnostic instrument.

The presence of nightly erections, as well as the degree of rigidity, may also be determined using a commercially available Velcro fastener-or postage stamps (19), whereby the patient is instructed to apply the tape around the base of his penis before retiring at night. In the presence of nightly erections, the tape will break along the perforation. However, the role of NPT beyond the confirmation of an existing diagnosis is yet to be determined. According to $D S M-I I I$, before a diagnosis is made, all possible organic causes have to be ruled out (10). The recent explosion of knowledge about vascular pathologies and other physical factors has contributed greatly to a better understanding of this disorder.

Measurement of penile blood pressure and penile blood flow by means of mercury strain gauge recordings, spectrography and Doppler techniques provides a more direct method of identifying the role of vascular obstruction in erectile dysfunctions (11). Methods for x-ray visualization of the genital vascular system include pelvic arteriography (12), phalloarteriography (13) and percutaneous cavernosography (14). These invasive approaches, when clinically indicated, can provide valuable information, but they remain difficult to implement and interpret.

The possible neuropathic contribution to erectile impairment may be evaluated indirectly by cystometrography (15) because the autonomic pathways that control erection and micturition are the same. Hence, today, genuine 
progress in diagnosis of erectile impotence has been achieved. The numerous physical and mental assessment devices lay a firm ground for diagnostic evaluation.

\section{TREATMENT APPROACHES}

The quest for a simple aphrodisiac that can cure erectile disorders dates back thousands of years. It was not until the development of psychoanalytic theory that psychodynamic concepts of sexual dysfunctions came to the fore. As a result of progress in psychoanalytic theory and technique, new approaches have evolved in the psychodynamic treatment of sexual dysfunctioning which are substantially different from a traditional psychoanalytic approach (16). The newer technique is flexible, depending on the psychodynamic needs of the patient. Therapy may be either on a one-to-one basis or may involve conjoint therapy with the patient's sexual partner, or even group therapy, or any combination of these.

This technique emphasizes current situational factors such as the relationship with the partner, traumatic circumstances and the source of the patient's anxiety. The recommendations may include specific experiential tasks similar to those prescribed by behavioral sex-therapists. The overriding objective of treatment is to diminish performance anxiety or to prevent its occurrence.

Medical and surgical treatments, designed to make penile-vaginal intercourse possible, are also available for this disorder; with an inflatable prosthesis, a fairly normal erection is now attainable. With orgasm lacking, many experience the use of a prosthesis as enabling only a "pseudo-coitus."

New methods of pharmacologic manipulation are being tried, based on the hypothesis that anxiety and sexual arousal inhibit erection by excessive alphaadrenoreceptor stimulation of sympathetic nervous tissue. Such measures are: 1) intermittent papaverine (vasodilator) injections (17); 2) self-injection of papaverine and phentolamine (alpha-adrenoreceptor antagonist) before intercourse; 3) self-injection of phenoxybenzamine (alpha-adrenoreceptor antagonist) (6) before intercourse and oral administration of Yohimbine ( $\mathrm{alpha}_{2}$-adrenoreceptor antagonist).

\section{DISCUSSION}

The treatment and understanding of erectile dysfunction has assumed a different outlook in recent years. Commonly held notions about erectile impotence of psychogenic origin are no longer viable, for example:

1. Absence of any demonstrable physical cause does not suggest psychogenic impotence because the physiologic mechanisms of erections still are not clear and routine examinations are not enough to reveal all of the relevant pathology involved. 
2. Erectile impotence of sudden onset, or occurring transiently and selectively, is not always the concomitant of psychogenic impotence, for it may appear in organic pathologies as well.

Warwick Williams (18) has reported significant vascular pathology even in young men (early twenties) presenting with a typical history of situational impotence.

3. The presence of morning erections does not indicate a psychogenic cause of a man's impotence. Such erections depend on whether the patient awakens from REM or non-REM sleep.

4. Nocturnal emissions are not indicative of impotence's being psychogenic either, because they designate ejaculatory rather than erectile competence (4)

Organic pathology in the etiology of this disorder is increasingly being appreciated. The list of organic causes of erectile impotence is exhaustive, although the reversible physical factors are only a few. Remarkable among such reversible factors are defects of hypothalamic-pituitary-gonadal axis (1).

1. Hypogonadotropic hypogonadism: Low serum testosterone levels are associated with pituitary tumors.

2. Hypergonadotropic hypogonadism: Low serum testosterone levels are associated with primary testicular failure.

3. Hyperprolactinemia: Bromocriptine administration brings forth prompt relief.

4. "External iliac steal syndrome," involving a shift of blood away from the erect penis to meet the needs of gluteal muscles engaged in vigorous movement. Normal potency may be restored by vascular bypass surgery.

5. Hyperthyroidism: $56 \%$ of such patients report erectile dysfunction. Propyl thiouracil administration results in return to potency.

6. Pickwickian Syndrome: $42 \%$ of men may be impotent. Hypoxia, depression of testosterone and impotence are all reversed by weight reduction (21).

An offending agent (such as drugs) producing erectile failure, major depression and susceptibility to alcohol are other causes that we can attribute to reversible agents (18).

There still remains a question; To what treatment modality is this disorder, and in particular, the form which has multiple etiologies, amenable? Before answering this question, it is worthwhile to survey clinical observations made in the course of sex-therapy with such patients.

1. Sexual performance anxiety is almost always present, even when organic causation is obvious $(4,16,18,19)$.

2. Even well-informed and educated men are unaware of age-related changes in their sexual response. 
3. Even in the presence of very daunting contributory physical factors, intensive sex therapy often produces successful results. Masters and Johnson (4) report a success rate of 73.8 percent for secondarily impotent men. The rate for primarily impotent men was 59.4 percent.

4. There is often a lack of proper communication between the patient and his sexual partner.

5. If untreated, this disorder may ultimately lead to total cessation of any type of sexual activity between the patient and his partner. Taking into consideration the above observations, the author proposes a course of sex-therapy for men with erectile impotence unless history, physical exam and routine lab work all indicate such reversible pathology as mentioned earlier. At least one psychogenic factor ("sexual performance anxiety"), universally involved in this disorder, may thus be resolved. This proposal takes into account the fact that extensive organic workup is very expensive and that any surgical intervention should not be expected to produce a profound change in an individual's basic adjustment to life. A combined approach by psychiatry and urology in the assessment and management of this condition is the preferred way to deal with this disorder.

\section{CASE ILLUSTRATION}

$\mathrm{Mr}$. A is a 56-year-old retired caucasian male known to have psoriasis, osteoarthritis and hypertension, medicated with hydrochlorothiazide, $25 \mathrm{mg}$ daily, indomethacin, 50 $\mathrm{mg}$ QID, and allopurinol, $300 \mathrm{mg}$ daily, presented a history of difficulty in getting and keeping erections for the last seven years. His problem started gradually. Currently, by foreplay, he can obtain erections that are $40-60 \%$ of previous erections and he can achieve penetration in $10 \%$ of his sexual attempts, but he loses the erections before ejaculation. He has morning erections five times a week that are $40-60 \%$ firm. He denies problems with libido and orgasm, but he has been a premature ejaculator for the last 10-12 years. He noticed a few years ago that sensation in his penis had lessened. Past medical history includes cancer of the lip eight years ago and knee surgery for arthritis.

Mr. A was born and raised on a farm near a small town in north Texas. He is the only son in his family. His mother had rheumatic heart disease and frequently suffered congestive heart failure. Despite her disability, she took good care of her family. Mr. A has great regard for his father too, but feels that if his father had been more strict Mr. A could have completed high school. Mr. A was drafted into the army at age 20 years and remained there for eight years. Subsequently, he worked as a heavy machine operator until his early retirement at age 55 years.

Sexual history revealed that he had his first heterosexual experience at age 13. His marriage at age 20 lasted for one year. The reason he gave for the divorce was too much interference by his mother-in-law. His second marriage lasted twenty years. He has two children from this marriage. Mr. A always had conflict with his wife over disciplining the children; it worsened, but he remained married because he wanted to give his children a better future. The sexual contact with his wife during the past few years occurred seldom, though he remained sexually active with two women friends in the neighborhood. After 
the death of his second wife a year ago, he started dating a woman who is partly disabled from an accident. He married her after two months of dating. She knew of his potency problems and willingly participated in sex therapy.

On mental status examination, Mr. A was cooperative and appeared somewhat upset with the urologist who referred him for psychiatric assessment. His mood was somewhat anxious and his affect was appropriate. He showed no evidence of severe psychopathology. Physical exam was unremarkable except for decreased tactile sensations on the right side of his glans penis. MMPI profile showed multiple problems with heightened anxiety and somatic complaints.

Penile/brachial hemodynamic indices were within normal limits. Evaluation of NPT was within the normal range for his age. His testosterone level was within normal limits. Thyroid function studies and prolactin were within normal limits. Mr. A denied smoking and drinking alcohol.

This anxious patient, distressed with his symptoms, had preoccupations of having to initiate sex at least twice a week in order to satisfy his wife and be a "good husband." Treatment was directed at his anxiety as well as at his ejaculatory dyscontrol. Coitus and ejaculation were prohibited. The couple was assigned a protocol of exercises. Five weeks after the start of therapy the patient had intercourse while the prohibition on doing so was still in effect. He began focusing on his own sexual drive rather than on any marital obligation towards his wife. He used sexual fantasy, received vigorous genital manipulation by his wife and learned to make love in a relaxed, comfortable position which was in no way limited by his severe osteoarthritis. A four-month follow-up revealed that the patient engages his wife in foreplay about twice a week and in coitus about once every three or four weeks. He did not indicate any interest in workup for possible pharmacological intervention.

\section{CONCLUSIONS}

The psychic or socioemotional needs of men with this disorder are tremendous. A psychiatric intervention, therefore, has to be extensive, not stopping with the identification or ruling out of psychosocial causes.

1. A known irreversible physical factor is not a contraindication for a careful trial of sex therapy.

2. Meticulous attention to all the involved accessible psychological issues, especially performance anxiety and interactional contributions from the man's relationship with his partner, is essential.

3. Pharmacological intervention may be used as adjunct to a behavioral approach. More controlled studies are required in this regard.

\section{REFERENCES}

1. Spark RF, White RA, Connolly PB: Impotence is not always psychogenic. JAMA 1980; 243:750-755

2. Kinsey AC, Pomeroy WB, Martin CF: Sexual Behavior in the Human Male. WB Saunders, 1948, p 804 
3. Bernstein AE, Warner GM: Psychodynamics of the neuroses, in An Introduction to Contemporary Psychoanalysis. New York, Jason Aronson, 1981, p 61

4. Masters W, Johnson V: Human Sexual Inadequacy. Boston, Little Brown, 1970, p 138, 211

5. Kaplan HS: Erectile dysfunction, in The New Sex Therapy. Brunner/Mazel, The New York Times Book Co., 1974, p 260-288

6. Brindley GS: Cavernosal alpha-blockade: a new technique for investigating and treating erectile impotence. Brit J Psychiatry 1983; 143:332-337

7. Fisher C, Gross J, Zuch J: Cycle of penile erection synchronous with dreaming (REM) sleep: preliminary report. Arch Gen Psychiatry 1965; 12:29-45

8. Karacan I: Evaluation of nocturnal penile tumescence and impotence, in Sleep and Waking Disorder: Indications and Techniques. Edited by Guilleminault G., Menlo Park, Calif: Addison-Wesley Pub Co, 1982, 343-71

9. Marshall P, Surridge D, Delva N: The role of nocturnal penile tumescence in differentiating between organic and psychogenic impotence: The first stage validation. Archives of Sexual Behavior 1981; 10

10. Diagnostic and Statistical Manual of Mental Disorders, Third Edition, Washington, DC, 1980, American Psychiatric Association, p 279

11. Gaskell P: The importance of penile blood pressure in cases of impotence. Can Med Assoc J 1971; 105:1047-51

12. Michal V, Kramar R, Popischal J, Hezhal L: Arterial epigastricocavernous anastomosis for treatment of sexual impotence. World J Surg 1977; 1:515-20

13. Michal V, Pospichal J: Phalloarteriography in the diagnosis of erectile impotence. World J Surg 1978; 2:239-47

14. Fitzpatrick T, Cooper JR: A cavernosogram study on the vascular competence of the human deep dorsal vein. J Urol 1975; 113:497-99

15. Ellenberg M: Impotence in diabetes: The neurological factor. Ann Intern Med 1971; 75:213-19

16. Marmor J: The psychodynamic approach to the treatment of sexual problems. in Eating, Sleeping and Sexuality. Treatment of Disorders in Basic Life Functions. Edited by Zales M. New York, Brunner/Mazel, 1981, p 226-235

17. Virag R: Intracavernous injection of papaverine for erectile failure. Lancet 1982; 2:938

18. Warwick W: Psychogenic erectile impotence-a useful or a misleading concept. Australian and New Zealand J Psychiatry 1985; 19:77082

19. Silber SJ: Impotence. Adv Intern Med 1984; 30:359-85

20. Van Unnik JG, Marsman JW: Impotence due to the external iliac steal syndrome treated by percutaneous transluminal angioplasty. J Urol 1984; 131:544-5

21. Semple PA, Graham A, Malcolm Y, Beastall GH, Watson WS: Hypoxia, depression of testosterone, and impotence in pickwickian syndrome reversed by weight reduction. Br Med J 1984; 289:801-2 